\title{
Investigating Cognitive Processes Underlying Reading in Arabic: Evidence from Typical and Poor Reading Performance
}

\author{
Haitham Taha ${ }^{1,2}$ \\ ${ }^{1}$ The Cognitive Lab for Reading and Learning-Sakhnin College for Teachers' Education, Sakhnin, Israel \\ ${ }^{2}$ Safra Brain Research Center for Learning Disabilities-Haifa University, Haifa, Israel \\ Email: htaha@macam.ac.il
}

Received August $23^{\text {rd }}, 2103$; revised September $27^{\text {th }}, 2013$; accepted October $24^{\text {th }}, 2013$

\begin{abstract}
Copyright (C) 2013 Haitham Taha. This is an open access article distributed under the Creative Commons Attribution License, which permits unrestricted use, distribution, and reproduction in any medium, provided the original work is properly cited. In accordance of the Creative Commons Attribution License all Copyrights (C) 2013 are reserved for SCIRP and the owner of the intellectual property Haitham Taha. All Copyright (C) 2013 are guarded by law and by SCIRP as a guardian.
\end{abstract}

\begin{abstract}
The current study has examined by which cognitive factors at the field of phonological and visual processing, rapid automatized naming and morphological awareness, contribute to reading and decoding abilities among typical and poor native Arabic readers. In the current study, the performances of two groups of participants, typical and poor readers were compared through tasks that examined their performance with regard to the areas of functions mentioned above in addition to other tasks that examined their performance in reading meaningful and pseudo words. The study's results have indicated that the visual and phonological processing skills play an important role in reading among typical and poor readers as well. Moreover, it was found that the visual and phonological processing skills of participants with poor reading skills were lower in comparison to participants with typical reading abilities.
\end{abstract}

Keywords: Phonological Processing; Morphological Processing; Visual Processing; R.A.N; Arabic Orthography

\section{Introduction}

The process of reading acquisition is regarded as complex and relies on the development of various cognitive processes. Many researchers suggest that during the process of reading acquisition, the reader learns the written representation of the phonemes of which the spoken words are composed, as during the process of reading, the reader can decode these phonemes according to the graphemes that represent them (Ziegler \& Goswami, 2005). The reader can correctly pronounce written words through processes of sequential blending (Adams, 1990; Bradely \& Bryant, 1978; Coltheart, 2005; Lundberg, Olofsson, \& Wall, 1980; Snowling, 2001; Stanovich, 1986; Treiman, 1993).

Many researchers also suggest that normal development of phonological processing skills, such as phonemic segmentation and phonemic blending, is acquired as the reader enjoys a normal phonological awareness regarding the speaking sounds which composed the spoken words (Abu-Rabia \& Taha, 2004, 2006; Goswami \& Bryant, 1990; Share, 1995; Snowling, Goulandris, \& Defty, 1996; Stanovich, 1988; Wagner \& Torgesen, 1987; Ziegler \& Goswami, 2005). Those phonological processing skills are found to be main contributor to reading acquisition in several alphabetic orthographies and are affected mutually by the exposure to print (Ziegler et al., 2010; Ziegler \& Goswami, 2005). Accordingly, the study at the field of the reading acquisition and its development discerns that among readers with difficulties, particularly those with reading disabil- ity, an inadequate performance in tasks that investigate phonological awareness was found (Snowling, 2001; Stanovich, 1986; Vellutino, Fletcher, Snowling, \& Scanlon, 2004).

Along with the previous assumption, Snowling (2001) suggests that heterogeneity between various readers concerning the control of the processes of phonological processing distinguishes between the sub populations of readers in the extent of their reading skills. In addition, such heterogeneity illustrates that readers with reading disability suffer from inadequate development of processes of phonological processing, as the level of difficulty in reading among this group is measured by the extent of inadequacy in these processes of processing.

Consistent with Snowling's assumption, research evidence argues that individual differences in the processes of reading and spelling are related to the processes of phonological processing (Goswami \& Bryant, 1990; Share, 1995; Snowling, Goulandris, \& Defty, 1996; Stanovich, 1988; Wagner \& Torgesen, 1987).

Appropriately, different developmental models in reading development (for example: Ehri, 1999; Frith, 1985), suggest that formation of a skilled reader is a matter of a transition from logographic stage where the child can identify forms of words that are familiar in his/her surrounding as symbols (such as his/her name etc.) to the alphabetic stage where the reader learns the letter-sound relationship and that reading of words becomes a matter of a process of phonological decoding that basically relies on a phonemic processes of segmentation and blending according to the grapheme sequence (the letters) and 
the pattern of the written word. By the repeated exposure to the patterns of words in the case of normal processes of reading and a normal development of the processes of decoding at the alphabetic stage, the child stores these patterns of words to which he/she was exposed during the process of reading. Consequently as children read these words again, they can more accurately and swiftly identify the pattern of the word according to its orthographic structure. This stage is called the orthographic stage or the consolidated one (Ehri, 1999; Frith, 1985).

Various researchers argue that in spite of the significant role of the phonological awareness in controlling the processes of reading, it is important to consider the contribution of other linguistic variables in achieving fluency in reading. In recent years, the research conducted in the field of reading acquisition highlights the importance of the morphological awareness and the development of the morphological lexicon among readers for the purpose of a normal acquisition of reading skills (BenDror, Bentin, \& Frost, 1995; Elbro \& Arnbak, 1996; Levin, Ravid, \& Rapaport, 2001; Nunes \& Bryant, 2009; Ravid, 2001; Senechal, 2000; Taha \& Siaegh-Haddad, submitted; Treiman \& Bourassa, 2000). The results of the studies that examined the reading acquisition among novice readers indicated that children eventually have a good intuitive knowledge regarding the morphology of the language (Clark \& Hecht, 1982). Accordingly, Carlisle (1995) points out that the extent of the morphological awareness at kindergarten years, which was measured by tasks of morphological differentiation successfully predicts the ability in reading comprehension at the second grade. In other words, the morphological awareness strengthens the skills that are related to reading such as the identification of words and even meta-linguistic ability such as reading comprehension (Tong et al., 2011).

In addition, consistent with the approach which suggests that individual differences in reading abilities are produced as a result of a variation in the extent of the control of the processes of phonological processing (Goswami \& Bryant, 1990; Share, 1995; Snowling, Goulandis, \& Defty, 1996; Stanovich, 1988; Wagner \& Torgesen, 1987), other researchers suggest that differences in the processes of morphological processing and morphological awareness contribute to inter-personal differences in the processes of literacy skills (Nunes, Bryant, \& Lindman, 2006; Rubin, 1991).

Other researchers argue that in addition to the contribution of processes of phonological and morphological processing to reading, other processes also predict reading such as automatization and the speed of retrieval and naming, particularly phonological naming to repeated visually presented forms (Denckla \& Cutting, 1999; Wolf, Bowers, \& Biddle, 2000). The argument of researchers who advocate the approach of the speed of retrieval and naming indicates that the process of phonological naming according to visual labels as measured in tasks of rapid naming (Denckla \& Rudel, 1974), is sort of analogy to the process of reading in which the reader is required to match the sound to the visual clue (The letter or the written form of words). On the other hand, such tasks can predict the success in the acquisition of skills of decoding and letter-sound relationship in the process of reading (Bowers \& Newby-Clark, 2002).

However, for the process of verbal retrieval according to the visual labels to occur, the verbal and visual processes need to occur simultaneously, a situation similar to the process of reading written words (for more details, see Breznitz, 2006). This process of timing or "synchronization" between the phonological processes and the processes of visual processing of the forms of word is considered as a fundamental process, as it may enable the reader to read words efficiently. Breznitz (2006) argues that the lack of synchronization between the processes certainly leads to a loss of the phonological and visual knowledge needed for reading words due to the limitation of the working memory. Therefore, there is a need for a "quick" work on this synchronized system to prevent inconsistency between the visual and phonological processes as the outcome could be a difficulty in reading words. This pace of work is called speed of processing (SOP) (Breznitz, 2006).

Eventually, it can be inferred that similar to explanations about the variation in the reading ability based on the approach of phonological processing, mentioned above, and the approach of morphological processing and the speed of retrieval, SOP indicates that variation in the speed of processing is a possible source for variation in reading ability since it is a possible reason for disability in synchronization between the processes during the processing of words. The processes of synchronization deal with the visual-phonological synchronization in the process of processing of words, though other researchers argue that the processes of visual processing are at the center of processes of reading and proved significant and distinctive in identifying normal readers and readers with difficulties (Everatt et al., 1999; Heiervang \& Hugdahl, 2003; Jaœkowski \& Rusiak, 2005).

A central research approach at the field of psychology of reading indicates that these processes of phonological decoding that occur during identification of words and the processing of the patterns of written words are directed through the resources of visual attention that need to be sufficiently available during the process (for more details, see Everatt, 1999). During reading, the process of words identification starts with the visual processing of the orthographic form of words. The eyes scan the written form through a series of movements of fixation and saccades. As the eyes are fixed on the word during the scanning, the situation is called fixation and as the eyes move toward the following word, the situation is called saccadic movement. These two movements of the eyes, fixation and saccades, play a significant role in centering the pattern of the scanned word at the fovea, the eye's most sensitive position, for the purpose of increasing the possibility that the word will be processed to the maximum. The success of the process of visual scanning necessitates mobilization of sufficient resources of visual attention. On the other hand, research on the psychology of reading indicates that disabilities in the processes of visual attention disturb the movements of the eyes during the process of reading of words (Everatt, et al., 1999; Heiervang \& Hugdahl, 2003; Jaœkowski \& Rusiak, 2005). Besides, the research in the field of psychophysiology and neuropsychology indicates that the visual areas at parietal lobes of the brain are related to focusing the movements of the eyes and to processes of visual attention (Glickstein, 2000; Goodale \& Milner, 2004; Milner \& Goodale, 1995). Beside, Kinsey et al., (2004) argue that the function of visual attention is particularly important during reading new words and pseudo words. The failure of readers with reading disability in reading pseudo words can be attributed to their failure in processes of visual processing of the written words' orthographic form (Heiervang \& Hugdahl, 2003).

This failure in the processes of processing that rely on processes of visual attention during reading leads to failure in de- 
tecting the position of the letter in the word, a thing that leads to reading errors of letters transposition and migration (Friedman \& Gvion, 2001). Studies that compared the performances of readers with reading disability versus normal readers in tasks that examined the processes of visual attention and spatial processing indicated that readers with reading disability achieved lower performance than readers with normal reading ability (Facoetti \& Turatto, 2000; Vidyasagar \& Pammer, 1999).

Consistent with the above mentioned review, it can be indicated that the research regarding the study of reading acquisition and the skills of recognition of words emphasizes the development of a variety of cognitive process. Accordingly and in light of the abovementioned review, the current study seeks to investigate by which phonological processing, automatized naming, morphological awareness and visual processes contribute to the ability of reading new unfamiliar words as well as familiar words in Arabic orthography which has unique characteristics. Hence, this study tries to identify the implications of the unique orthographic and linguistic characteristics of the written Arabic language on the cognitive processes related to the reading process.

\section{Reading in Arabic Orthography}

Studies in the field of reading in Arabic orthography argue that the process of phonological processing is significantly related to the processes of reading in Arabic orthography (AbuRabia, 2001, 1997a, 1997b, 2007). Furthermore, other researchers argue that the development of phonological awareness, at the center of the processes of phonological processing, among native Arab readers is highly influenced from diglossia; a situation that may be clearly manifested during the acquisition of reading and spelling (Abu-Rabia \& Taha, 2005; SaieghHaddad, 2003, 2004). In unique linguistic situation of the Arabic language, the distance within different linguistic domains between the spoken language and dialect to the written language acquired by children at the formal framework of school is a classic situation of diglossia (Ayari, 1996; Ferguson, 1959; Taha, 2013). Other studies also suggest that process of morphological processing have high importance regarding controlling processes of reading at the Arabic orthographic system, due to the morphological richness of the Arabic language (for more details, see Abu-Rabia, 2007; Abu-Rabia \& Taha, 2005; Taha, 2013). Beside to the specific linguistic features of the Arabic language and their effect on reading, recent studies suggest that the specific orthographic features of the written Arabic may affect the process of word recognition in Arabic (Ibrahim, Eviatar, \& Aharon Peretz, 2002; Taha, Ibrahim, \& Khateb, 2013). Two main unique features are account within this frame, the level of connectedness of the letters within the word and the existence of dots and vowelization marks above and below the letters within the written word. A former study conducted by Ibrahim, Eviatar and Aharon-Peretz (2002) showed that the orthographic structure of the Arabic language may decelerate the pace of the visual processing during reading. While other studies found that this effect of orthographic structure on word recognition might be modulated by development and exposure to print (Khateb et al., Submitted). Yet, so far studies have not investigated the contribution of processes of visual processing and the speed of naming according to visual stimuli besides the contribution of the processes of phonologi- cal and morphological processing to the ability of reading and decoding, neither familiar nor unfamiliar words, in the Arabic language. Also, investigating the differences of the contribution of the abovementioned factors to reading among typical readers versus poor readers have not been conducted. It should be noted that a study conducted by Abu-Rabia, Share and Mansour, (2003) examined the processes of performance in tests of visual memory among typical readers and readers with reading disability at the same chronologic age group and reading age and their contribution to reading words, as no differences were found in the performances of participant in the tests of visual memory. The study of Abu-Rabia and his colleagues focuses on examining the process of global and analytical visual memory but it does not directly focus on examining the processes of sequential visual scanning and search. While the process of orthographic processing of the orthographic words patterns relies on processes of visual scanning and processing and sequential visual processing in addition to processes of visual identification. Accordingly, due to the fact of the orthographic complexity of the written Arabic, where letters shapes changes according to their position in the written form and according to the letters that precede and follow them. And due to the visual intensity that exists as a result of the vowelization marks above and under the letters within the written words. Accordingly, the current study assumes that the processes of visual sequential processing and distinction will have an essential contribution to achieving efficient processes of reading in the Arabic language beside to other cognitive abilities that were found to affect reading in Arabic like the phonological and morphological skills. In general, it is important to investigate the contribution of the different cognitive and linguistic skills that were reported during the abovementioned review on reading in Arabic orthography among typical and poor readers.

\section{Methods}

Participants. 67 native Arab children studying at Arab school in north of Israel have participated in the study. The participants were divided into two groups according based on their performances in the test of reading words in context. From the first sample, children whose performance was below $70 \%$ at the task of reading meaningful words were defined as children with reading difficulties. The chosen words were regarded as highly frequent taken from pedagogical texts. A skilled reader can identify these words at a high level of accuracy (Taha \& Saiegh-Haddad, Submitted). Thus readers whose percentage of accuracy in reading these words is below $70 \%$ can be regarded as reader with reading difficulty. The group of typical readers is those who achieve above $90 \%$ in reading meaningful words. The reading screening task included 60 meaningful punctuated words $(\alpha=0.82)$. The group of poor readers included 11 boys and 21 girls whose age average was $12.04(\mathrm{SD} \pm 0.29)$. The group of typical readers included 18 boys and 17 girls whose age average was $12.12(\mathrm{SD} \pm 0.39)$ years old. All participants were from the middle class of socioeconomic status.

The participants in the two groups took part in tasks that examined reading meaningful words, pseudo words, processes of phonological processing, automatic naming, orthographic and morphological awareness and processes of visual processing.

Procedure. The testing procedures were conducted at the school in a quiet room dedicated specifically for the purpose of 
current study. Testing procedure took place during the regular school days of the week. Tests were conducted on a one-on-one basis. The order of the tests was counterbalanced across participants.

\section{Material and Stimuli}

\section{Rapid Automatized Naming (R.A.N) (Denckla \& Rudel, 1974)}

Naming of letters. A sheet of 5 Arabic letters, ten-times randomly repeated, was presented before the participants, who was asked to name the 50 letters at the fastest possible pace.

Digit naming. A sheet of 5 digits, ten-times randomly repeated was presented for each participant who was asked to name the 50 digits at the fastest possible pace.

Naming of objects. A sheet of 5 pictures of objects ten-times randomly repeated was presented before each participant who was asked to name the 50 pictures at the fastest possible pace.

\section{Phonological Processing}

Phonemic Deletion. The test is composed from 20 items. Within each item of the test, words were presented Auditory before the participant who was eventually asked to omit a phoneme from the word and pronounce the word without the omitted phoneme $(\alpha=0.86)$.

Phonemic Blending. The test is composed from 10 items. Within each item of the test, phonemes were presented before each participant who was asked to combine the phonemes sequentially and to submit the produced word $(\alpha=0.91)$.

Short-term phonological memory. Series of digits was presented before the participants who were asked to repeat the series again after hearing it through an immediate retrieval from their memory. Each item included two series with a same number of digits. The series begins with two digits in the first item and for each additional item one digit to each series. Each participant score was calculated as the total number of the correct series were retrieved $(\alpha=0.93)$.

Phonological Working memory. Audio series of digits were presented before the participants who were asked eventually (after hearing the series) to repeat it again by an immediate retrieval from their memory but in an opposite order. Each item included two series. The series starts with two digits in the first item and in each additional item one digit for each series. Each participant score was calculated as the total number of the correct series were retrieved $(\alpha=0.91)$.

\section{Morphological Awareness}

Morphological decision task. This task included 15 items. Each item included five words, four of which are derived from the same root and the fifth word is morphologically different but phonologically and orthographically similar to the other four words. The participant was asked to identify and circle the word which is different concerning its morphological relation$\operatorname{ship}(\alpha=0.85)$.

\section{Visual Processing}

Visual Perception Test (Beery, 1997). The test included 27 items. Each item has a target image and a number of other images below. The participant was asked to identify the image that exactly fit in with the target image using visual distinction processes. The level of the test's difficulty was at an increasing pace.

Visual search test of the diamond shape (Rudel, Denckla, \& Broman, 1978). The participant was asked to mark the target image in a sheet that included a lot of distractors. The target image appeared 14 times randomly in the sheet.

Visual search test of a series of digits (592) (Rudel, Denckla, \& Broman, 1978). The participant was asked to mark the series of digits (592) in a sheet that included a lot of distractors (series from other digits). The target series appeared 14 times randomly in the sheet.

\section{Reading Tests}

Reading pseudo words. The participant was asked to read a list of 22 pseudo words connected according to common form in the Arabic orthography and conform to words at the age of orthographic exposure. The reader has never been exposed to these words, meaning that the words were regarded as new ( $\alpha=$ $0.79)$.

Reading meaningful words. The participant was asked to read a list that included 56 familiar, meaningful and fully-punctuated words. The words conformed to the level of difficulty and exposure according to the participant's age $(\alpha=0.85)$.

\section{Results}

Using the model of stepwise regression indicates that there is a significant correlation between the processes of visual distinction as measured by the visual perception test and processes of visual search as measured by the test of searching the series of digits, but not by the test of visual searching of the visual shape, to reading meaningful and pseudo words. Calculating Person correlation indicates that in reading pseudo words there is a significant and positive correlation $(r=0.34, p<0.01)$ with the processes of visual distinction measured through the Beery test. In addition, regarding the reading of pseudo words, a significant positive correlation was found with the processes of visual searching of the series of digits $(r=0.32, p<0.01)$. Also concerning reading regular meaningful words, a signifycant positive correlation was found with the performance in the task of visual distinction $(\mathrm{r}=0.51, p<0.001)$. In addition, a positive correlation was found with the performance in the test of visual searching for the series of digits $(r=0.34, p<$ $0.01)$.

Significant correlation was found between the processes of phonological processing as examined in the tests of phonemic blending and phonemic omission to the processes of reading. A positive and significant correlation was found between the processes of phonemic blending and phonemic omission to reading pseudo words $(r=0.28, p<0.05$ and $r=0.5, p<0.001$ respectively). Also positive and significant correlation was found between the processes of phonemic blending and phonemic omission to reading meaningful and regular words $(r=0.5, p<$ 0.001 and $r<0.53, p<0.001$ ).

A positive and significant correlation was also found between the phonemic blending and working memory $(\mathrm{r}=0.27, p$ $<0.03$ ), in addition to the positive correlation that was found between the processes of phonemic omission and the processes of working memory $(r=0.4, p<0.01)$.

From the above analysis, based on the model of regression, it 
can be indicated that the variables which added to the regression model explain $53 \%$ of the variance in the process of reading meaningful words beyond the two populations of the study (see Table 1). The first variable is the ability of phonemic deletion $\left(R^{2}=0.29\right)$. The second variable is the performance in the test of visual distinction of Beery $\left(R^{2}=0.12\right)$. The third variable is the search for symbols (diamond test) $\left(R^{2}=0.08\right)$ and the fourth is phonemic blending $\left(R^{2}=0.04\right)$.

In reading pseudo words $31.6 \%$ of the explained variance was explained by the variables of phonemic omission $\left(R^{2}=\right.$ $0.244)$ as the second variable was the visual search for series of digits $\left(R^{2}=0.072\right)$ (see Tables 1 and 2).

According to the analysis conducted separately on the two groups of readers regarding reading meaningful words, $34.2 \%$ of variance within the poor readers was explained significantly by phonemic blending and visual search of digits $\left(R^{2}=0.229\right.$, and $R^{2}=0.113$ respectively). Besides, $49.5 \%$ of variance was found among the group of participants with typical reading abilities was significantly explained by the following variables; phonemic omission, naming of objects, naming of digits and working memory $\left(R^{2}=0.161, R=0.116, R^{2}=0.141\right.$, and $R^{2}=$ 0.077 respectively) (see Tables 3 and 4).

Regarding reading pseudo words, among the poor readers group $29.6 \%$ of variance was significantly explained by the phonemic omission and the visual search for digits $\left(R^{2}=0.194\right.$, and $R^{2}=0.102$ respectively)

Among the groups of readers with typical reading abilities, $32.6 \%$ of variance in reading pseudo words was significantly explained by working memory and object naming $\left(R^{2}=0.185\right.$ and $R^{2}=0.114$ (see Tables 5 and 6).

The analysis of variance indicated that there was a significant

Table 1.

Stepwise Regression Analysis results of predictors for reading words beyond to the both groups of participants.

\begin{tabular}{cccc}
\hline Predictors & $\mathrm{R}^{2}$ & $\mathrm{R}^{2}$ Change & $\mathrm{F}$ \\
\hline Phonological Deletion & 0.29 & 0.29 & $25^{* *}$ \\
Visual perception (distinction-Beery) & 0.37 & 0.12 & $19.12^{* *}$ \\
Visual search-Diamond & 0.45 & 0.08 & $16.88^{* *}$ \\
Visual search-592 & 0.49 & 0.04 & $14.57^{* *}$ \\
\hline
\end{tabular}

${ }^{* *} p<0.001$.

Table 2.

Stepwise Regression Analysis results of predictors for reading pseudo words beyond to the both groups of participants.

\begin{tabular}{cccc}
\hline Predictors & $\mathrm{R}^{2}$ & $\mathrm{R}^{2}$ Change & $\mathrm{F}$ \\
\cline { 2 - 3 } Phonological Deletion & 0.24 & 0.244 & $20.98^{* *}$ \\
Visual search-592 & 0.31 & 0.072 & $14.75^{* *}$ \\
${ }^{* *} p<0.001$. & & &
\end{tabular}

Table 3.

Stepwise Regression Analysis results of predictors for reading words within poor readers group.

\begin{tabular}{cccc}
\hline Predictors & $\mathrm{R}^{2}$ & $\mathrm{R}^{2}$ Change & $\mathrm{F}$ \\
\hline Phonological Blending & 0.229 & 0.229 & $8.8^{*}$ \\
Visual search-(592) & 0.342 & 0.113 & $7.55^{*}$ \\
\hline${ }^{*} p<0.05$. & & &
\end{tabular}

Table 4.

Stepwise Regression Analysis results of predictors for reading words among typical readers group.

\begin{tabular}{cccc}
\hline Predictors & $\mathrm{R}^{2}$ & $\mathrm{R}^{2}$ Change & $\mathrm{F}$ \\
\hline Phonological deletion & 0.161 & 0.161 & $6.31^{*}$ \\
Speed naming of objects (R.A.N) & 0.277 & 0.116 & $6.11^{*}$ \\
Visual search-592 & 0.418 & 0.141 & $7.41^{*}$ \\
Phonological working memory & 0.495 & 0.077 & $7.36^{*}$ \\
\hline
\end{tabular}

${ }^{*} p<0.05$, Abbreviation: R.A.N (Rapid Automatized Naming).

Table 5.

Stepwise Regression Analysis results of predictors for reading pseudo words among poor readers group.

\begin{tabular}{cccc}
\hline Predictors & $\mathrm{R}^{2}$ & $\mathrm{R}^{2}$ Change & $\mathrm{F}$ \\
\hline Phonological deletion & 0.194 & 0.194 & $7.2^{*}$ \\
Visual search-(592) & 0.296 & 0.102 & $6.1^{*}$ \\
\hline
\end{tabular}

${ }^{*} p<0.05$.

Table 6.

Stepwise Regression Analysis results of predictors for reading psuedo words among typical readers group.

\begin{tabular}{cccc}
\hline Predictors & $\mathrm{R}^{2}$ & $\mathrm{R}^{2}$ Change & $\mathrm{F}$ \\
\hline Phonological working memory & 0.418 & 0.185 & $7.49^{*}$ \\
Speed naming of objects (R.A.N) & 0.495 & 0.141 & $7.74^{*}$ \\
\hline
\end{tabular}

${ }^{*} p<0.05$, Abbreviation: R.A.N (Rapid Automatized Naming).

difference between the group of typical readers and the group of poor readers in reading pseudo words $[F(1,65)=32.62, p$ $<0.001]$ (see Table 7). In addition such significant difference was also found between the two groups of participants in reading meaningful words $[F(1,65)=64.38, p<0.001]$. Also a significant difference was found between the two groups in the performance in the tests of phonological processes that include phonemic blending and phonemic omission $[F(1,65)=5.71, p$ $<0.05$, and $F(1,65)=10.43, p<0.05]$. Also the difference was significant between the two groups in the performance of the working memory test $[F(1,65)=7.047, p=0.01]$.

The analysis of variance for the performance in the tests of visual processing indicated a significant difference between the two groups of participants in the test of visual search for series of digits and the visual distinction as was tested by the visual perception test $[F(1,65)=5.4, p<0.05$ and $F(1,65)=23.45, p$ $<0.01]$.

\section{Discussion}

The study's findings clearly indicate that visual processing capacities and variables relevant to processes of phonemic processing predict reading in Arabic. Visual processing capacities that have been basically examined through tasks of visual distinction and visual scanning and search have significant correlation with the ability of reading pseudo words and meaningful words as well. Yet, it can be indicated that the correlation between the processes of visual distinction and reading meaningful words is higher than the correlation with reading pseudo words, but still, the correlations are significant. It can be inferred that reading pseudo words highly rests on the processes of phonological processing, generally on the processes of phonological working memory that is required in the process of 
Table 7.

Averages and standard deviation for the performances in the different tasks for each group of readers and the F value for the ANOVA between the groups.

\begin{tabular}{cccccc}
\hline & \multicolumn{3}{c}{ Poor Readers } & Typical Readers & \\
\hline Test & M & SD & M & SD & F value \\
R.A.N objects & 39.93 & 7.24 & 37.33 & 7.31 & n.s \\
R.A.N letters & 27.42 & 4.34 & 26.88 & 6.23 & n.s \\
R.A.N Digits & 23.31 & 3.1 & 21.41 & 4.63 & n.s \\
Phonological blending & 18.34 & 2.56 & 19.45 & 0.98 & $5.71^{*}$ \\
Phonological deletion & 16.28 & 2.14 & 17.85 & 1.84 & $10.43^{* *}$ \\
Short-term phonological memory & 7.78 & 1.93 & 8.31 & 2.63 & n.s \\
Phonological working memory & 4.125 & 1.31 & 4.97 & 1.29 & $7.05^{*}$ \\
Reading pseudowords & 17.03 & 2.65 & 19.97 & 1.42 & $32.62^{* * *}$ \\
Reading words & 45.21 & 5.65 & 53.14 & 1.41 & $64.38^{* * *}$ \\
Visual search (592) & 9.87 & 1.82 & 10.57 & 2.7 & n.s \\
Visual search-Diamond & 11.12 & 2.23 & 12.25 & 1.73 & $5.39^{*}$ \\
Visual distinction (Beery) & 20.97 & 2.3 & 23.65 & 2.2 & $23.45^{* * *}$ \\
Morphological awareness & 13.31 & 2.04 & 13.8 & 2.08 & n.s \\
\hline
\end{tabular}

${ }^{*} p<0.05,{ }^{* *} p<0.01,{ }^{* * *} p<0.001$, n.s $=$ non significant.

decoding during the reading of pseudo words in particular. Though, a significant correlation was found between the proc esses of distinction and visual processing to the process of reading pseudo words. This finding clearly indicates that reading unfamiliar words in Arabic orthography is associated with visual processing and processes of phonological processing.

In reading regular words, a high and significant correlation was received between the processes of visual distinction and the processes of reading, as it was also found that the variable of visual distinction significantly explains part of the variation in reading regular meaningful words. The finding indicates that there is a significant reliance on processes of visual processing of the orthographic pattern of words during reading. Accordingly, among participants in the two groups, it was found that the processes of visual processing play an important role in identifying familiar words. This finding shows that the process of reading words visually integrates processes linked to the processing of orthographic structure and the processes of phonological processing.

Various theories suggest that during the reading, there is synchronization between visual and phonological process, as an efficient synchronization which is the result of typical development of the processes of processing increases the probabilities that the process of reading and word identification will occur appropriately (Breznitz, 2006). The study's result shows that readers in Arabic orthography rely on processes of visual processing when reading orthographically regular and familiar words as well as new and unfamiliar words. The results also emphasize the significant difference between the group of participants with difficulties and the group of those who succeed in the performances related to tasks that examine visual processing. Similarly, significant difference was found between the two groups in task that examine phonological processing and phonological working memory that relates to processes of reading. this finding advocates the claim that interpersonal differences in reading abilities can be explained not only through differences in the processes of visual processing (Everatt, 1999; Facoetti \& Turatto, 2000; Vidyasagar \& Pammer,
1999), but also, through differences in the processes of phonological processing, as many researchers have suggested (Snowling, 2001)

More specifically, it can be suggested that in the case that the particular orthographic structure of the written word in the Arabic language places the reader under cognitive burden while performing the reading, a situation that necessitates him/her to try to invest visual resources for the sake of the task in addition to the processes of phonological processing that simultaneously occur (Ibrahim, Eviatar, \& Aharon-Peretz, 2002; Taha \& Khateb, Submitted). In the processes of synchronization terms, it can be indicated that a high level of synchronization between processes of visual and phonological processing is required by readers in the Arabic orthography for the purpose of an accurate reading.

Regarding visual processing during the reading of words, it is acceptable to point at two basic eye movements that occur during the reading for the purpose of performing the visual scanning for the form of the written word. The processes of visual scanning are the first stage in the reception of the orthographic form visually before the grapheme-phonemic transduction happens. Performing the process in a controlled and sequential way may increase the possibility that the reader will succeed to read appropriately. The study provides evidence for the importance of the processes of visual scanning and processing during the reading. Yet, it is still interesting to examine whether there is sequential processing at the level of letters, while reading pseudo words, whereas the processing will be at the global level when reading familiar words. The study's results underscore that there is a positive correlation between the sequential visual scanning and the global distinction to reading pseudo words and familiar words. Yet it can be suggested that a specific answer to such question is to be received in a study that investigates the eye movements during reading pseudo and regular words.

Besides, we cannot ignore the fact that the processes of phonological processing play a primary and essential role in reading and decoding familiar and unfamiliar words as well (Goswami \& Bryant, 1990; Share, 1995; Snowling, Goulandris, \& Defty, 1996; Stanovich, 1998; Wagner \& Torgesen, 1987). A specific look into the relation between the performances in the various tasks indicates that there is a significant correlation between the performance of tasks that examine phonological processing, phonemic omission and phonemic blending to the processes of phonological working memory. It can be suggested that the fact of the existence of this high correlation in the performance between tasks and the nature of these tasks indicates that the processes of phonological working memory are the primary factor on which the process of phonological processing relies and that tasks that examine processes of phonological processing, such as phonemic omission and phonemic blending, are actually tasks that examine phonological processing which basically relies on phonological working memory (Bradely \& Bryant, 1987). This claim concerning the contribution of processes of phonological processing to the processes of reading, in particular at the Arabic orthography, is advocated by various studies (Abu-Rabia, 1997a, 1997b, 2003, 2007). Similarly, other researchers suggest that the development of phonological awareness which constitutes a basis for the processes of phonological processing among native Arab readers is evidently influenced by diglossia, a situation that may be manifested during reading and writing acquisition particularly 
among children with difficulties (Saiegh-Haddad, 2003, 2004; Taha, 2013). The study's results reveal that there is a significant difference in the ability of phonological processing between poor and typical readers. It can be suggested that the groups of readers with reading difficulties experience difficulty in the processes of phonological processing as a result of individual developmental factors and also due to the impact of diglossia on the development of the phonological awareness among this group. Consequently, the phonological structure of the literary Arabic language which is the language studied in reading and the distance between the literary and spoken language constitutes more burden on the typical development of the processes of phonological processing, specifically among people with poor developmental potential to this skill. The main conesquences of such negative contribution of diglossia may be obviously manifested in difficulties in reading and decoding acquisition.

Concerning the processes of visual processing in the same context, it can be suggested that variance in the processes of visual processing points at primary cognitive developmental difficulties that impede the success in reading, especially in orthographies that have complex structure. Moreover, the orthographic structure of written words, specially, unfamiliar words that are not stored as consolidated orthographic patterns in the orthographic lexicon constitutes a burden during the processes of decoding, as processes of visual scanning and processing of the word's pattern are required. This situation of sequential visual processing or visual distinction that can be called the processes of visual processing may become more complex and packed during reading, decoding and orthographic processing in Arabic language due to the complexity of its orthographic features. Thus people with developmental difficultties in visual processing capacities may experience difficulties at a more significant level than those enjoying a normal functioning in these processes of processing. Thus based on the abovementioned analysis, the phonological status of the literary Arabic language and its orthographic status emphasize the developmental cognitive abilities that set the basis for the acquisition of reading skills I.e. the processes of phonological and visual processing.

Besides, the current study examines the process of the speed of verbal retrieval according to grapheme, visual and numerical stimuli, the so-called "Rapid automatized naming". However, there was no significant and sequential correlation between those processes and the processes of reading and decoding. It can bee seen that the primary components during reading in Arabic orthography are the processes of visual and phonological processing, as these processes are at the processing level and not only at the identification level. In other words, the verbal naming according to the visual stimulus basically rests on identification and retrieval, while the process of reading rests on variety of complex processing, specially reading in a complex orthography such as Arabic. Thus it is hard to confirm the claim that the processes of verbal naming according to the visual label constitute pure analogy for the processes of reading (Denckla \& Cutting, 1992; Wolf \& Bowers, 1999; Wolf, Bowers, \& Biddle, 2000). Yet it can be suggested that the speed of processing, especially the synchronization between the processes of visual and phonological processing is responsible for reading accuracy (Breznitz, 2006). The speed of processing may bridge difficulties in the processes of working memory that are produced due to the cognitive burden during the proc- essing. The faster the processing is, the coordination between the two processing will be and the probability of reading accuracy increases accordingly. Though this argument need to be further investigated through specific study.

The study's results reveal that the variable of morphological awareness does not have significant correlation with the performance in the reading tasks. Yet examination the task through which the morphological awareness is studied reveals that the task that basically examines morph-orthographic awareness and that the performance among the two populations was similar. The finding indicates that the nature of the task that examines morphological awareness through the reliance on processes of deduction of semantic links between words is not that task that purely examines morphological awareness, but rather, a task that examines awareness to semantic and morphological links between words, as participants was able to rely on the semantic links between words for the purpose of deduction of words that are not morphologically related to the rest of the words. Also, given that the reader is not aware to this linguistic fact, he/she can conclude that the word that does not semantically relate to the rests of the words is the odd word also if he/she does not enjoy a good morphological awareness. It can be inferred that the lack of the task's specificity regarding the mission fails to accurately distinguish those with good morphological awareness and those whose morphological awareness is inadequate and even loses the sensitivity of distinction people with normal abilities and those with difficulties due to the reliance on semantic clues. Thus, it can be suggested that examining the morphological awareness should occur at various levels for the purpose of ensuring the examination of the skills in a complete way.

In sum, the study's results raise a very important point suggesting that the process of reading in Arabic orthography necessitates normal functions of visual processing beside to the phonological processing abilities. This may make the process of orthographic visual processing more efficient either during a sequential decoding of new words or during the processes of identification of familiar words.

\section{REFERENCES}

Abu-Rabia, S. (1997a). Reading in Arabic orthography: The effect of vowels and context on reading accuracy of poor and skilled native Arabic readers in reading paragraphs, sentences, and isolated words. Journal of Psycholinguistic Research, 26, 465-482. http://dx.doi.org/10.1023/A:1025034220924

Abu-Rabia, S. (1997b). Reading in Arabic orthography: The effect of vowels and context on reading accuracy of poor and skilled native Arabic readers. Reading and Writing: An Interdisciplinary Journal, 9, 65-78. http://dx.doi.org/10.1023/A:1007962408827

Abu-Rabia, S. (2001). The role of vowels in reading Semitic scripts: Data from Arabic and Hebrew. Reading and Writing: An Interdisciplinary Journal, 14, 39-59. http://dx.doi.org/10.1023/A:1008147606320

Abu-Rabia, S. (2007). The role of morphology and short vowelization in reading Arabic of normal and dyslexic readers in grades 3, 6, 9, and 12. Journal of Psycholinguistic Research, 36, 89-106. http://dx.doi.org/10.1007/s10936-006-9035-6

Abu-Rabia, S., \& Taha, H. (2004). Reading and spelling error analysis of native Arabic dyslexic readers. Reading and Writing: An Interdisciplinary Journal, 17, 651-689. http://dx.doi.org/10.1007/s11145-004-2657-x

Abu-Rabia, S., \& Taha, H. (2005). Reading in Arabic orthography: Characteristics, research findings, and assessment. In R. M. Joshi, \& P. G. Aaron (Eds.), Handbook of orthography and literacy (pp. 321- 
338). New York: Routledge.

Abu-Rabia, S., \& Taha, H. (2006). Phonological errors predominate in Arabic spelling across grades 1-9. Journal of Psycholinguistic Research, 35, 167-188.

http://dx.doi.org/10.1007/s10936-005-9010-7

Abu-Rabia, S., Share, D., \& Mansour, M. (2003). Word recognition and basic cognitive processes among reading-disabled and normal readers in Arabic. Reading and Writing: An Interdisciplinary Journal, 16, 423-442. http://dx.doi.org/10.1023/A:1024237415143

Adams, M. (1990). Beginning to read: Thinking and learning about print. Cambridge, MA: MIT Press.

Ayari, S. (1996). Diglossia and illiteracy in the Arab world. Language, Culture and Curriculum, 9, 243-253. http://dx.doi.org/10.1080/07908319609525233

Beery, E. K. (1997). The Beery-Buktenica developmental test of visual motor integration with supplemental developmental tests of visual perception and motor coordination. New Jersey: Modern Curriculum Press.

Ben-Dror, I., Bentin, S., \& Frost, R. (1995). Semantic, phonologic, and morphologic skills in reading disabled and normal children. Reading Research Quarterly, 30(4), 876-893.

http://www.jstor.org/stable/748202 http://dx.doi.org/10.2307/748202

Bowers, P. G., \& Newby-Clark, E. (2002). The role of naming speed within a model of reading acquisition. Reading and Writing, 15, 109-126. http://dx.doi.org/10.1023/A:1013820421199

Bradly, L., \& Bryant, P. E. (1978). Difficulties in auditory organization as a possible cause of reading backwardness. Nature, 271, 746-747. http://dx.doi.org/10.1038/271746a 0

Breznitz, Z. (2006). Fluency in reading: Synchronization of processes. London: Lawrence Erlbaum Associates.

Carlisle, J. F. (1995). Morphological awareness and early reading achievement. In L. B. Feldman (Ed.) Morphological aspects of language processing (pp 189-209). Hillsdale, NJ: Lawrence Erlbaum.

Clark, E. V., \& Hecht, B. F. (1982). Learning to coin agent and instrument nouns. Cognition, 12, 1-24.

http://dx.doi.org/10.1016/0010-0277(82)90027-0

Coltheart, M. (2005). Modelling reading: The dual-route approach. In: M. J. Snowling \& C. Hulme (Eds.), The Science of Reading. Oxford: Blackwells Publishing. http://dx.doi.org/10.1002/9780470757642

Denckla, M. B., \& Cutting, L. E. (1999). History and significance of rapid automatized naming. Annals of Dyslexia, 49, 29-42. http://dx.doi.org/10.1007/s11881-999-0018-9

Denkla, M. B., \& Rudel, R. G. (1974). Rapid automatized naming of pictured objects, colors, letters and numbers by normal children. Cortex, 10, 186-202.

http://dx.doi.org/10.1016/S0010-9452(74)80009-2

Ehri, L. C. (2005). Learning to read words: Theory, findings, and issues. Scientific Studies of Reading, 9, 167-188. http://dx.doi.org/10.1207/s1532799xssr0902 4

Elbro, C., \& Arnbak, E. (1996). The role of Morpheme recognition and morphological awareness in dyslexia. Annals of Dyslexia, 46, 209-240. http://dx.doi.org/10.1007/BF02648177

Everatt, J. (1999). Reading and dyslexia: Visual and attentional processes. New York: Routledge.

Everatt, J., McCorquodale, B., Smith, J., culverwell, F., wilks, A., Evans, D., Kay, M., \& Baker, D. (1999). Association between reading ability and visual processes. In: Everatt, J (Ed.), Reading and dyslexia: Visual and attentional processes (pp 1-39). New York: Routledge.

Facoetti, A., Paganoni, P., Turatto, M., Marzola, V., \& Mascetti, G. G. (2000). Visual-spatial attention in developmental dyslexia. Cortex, 36, 109-123. http://dx.doi.org/10.1016/S0010-9452(08)70840-2

Ferguson, C. A. (1959). Diglossia. Word, 14, 47-56

Friedmann, N., \& Gvion, A. (2001). Letter position dyslexia. Cognitive Neuropsychology, 18, 673-696. http://dx.doi.org/10.1080/02643290143000051

Frith, U. (1985). Beneath the surface of developmental dyslexia. In: Patterson, K. E., Marashall, J. C., \& Coltheart, M. (Eds.), Surface dyslexia. (pp 301-330). London: Lawrence Erlbaum Associates.
Glickstein, M. (2000). How are visual areas of the brain connected to motor areas for the sensory guidance of movement? Trends in $\mathrm{Neu}$ rosciences, 23, 613-617. http://dx.doi.org/10.1016/S0166-2236(00)01681-7

Goodale M, A., \& Milner A, D. (2004). Sight unseen: An exploration of conscious and unconscious vision. New York: Oxford University Press.

Goswami, U., \& Bryant, P. (1990). Phonological skills and learning to read. Hove: Erlbaum.

Heiervang, E., \& Hugdahl, K. (2003). Impaired visual attention in children with dyslexia. Journal of learning disabilities, 36, 68-73. http://dx.doi.org/10.1177/00222194030360010801

Ibrahim, R., Eviatar, Z., \& Aharon Peretz, J. (2002). The characteristics of the Arabic orthography slow it's cognitive processing. Neuropsycholgy, 16, 322-326. http://dx.doi.org/10.1037/0894-4105.16.3.322

Jaœkowski, P., \& Rusiak, P. (2005). Posterior parietal cortex and developmental dyslexia. Acta Neurobiologiae Experimentalis (Wars), 65, 79-94.

Khateb, A., Khateb, M., Taha, H., \& Ibrahim, R. (Submitted). The effect of the internal connectedness of written Arabic words on the process of the visual recognition: A developmental study.

Kinsey, K., Rose, M., Hansen, P., Richardson, A., \& Stein, J. (2004). Magnocellular mediated visual-spatial attention and reading ability. Neuroreport, 15, 2215-2218.

Levine, I., Ravid, D., \& Rapaport, S. (2001). Morphology and spelling among Hebrew-speaking children: From kindergarten to first grade. Journal of Child Language, 28, 741-772.

http://dx.doi.org/10.1017/S0305000901004834

Lundberg, I., Olofsson, A., \& Wall, S. (1980). Reading and spelling skills in the first school years predicted from phonemic awareness skills in kindergarten. Scandinavian Journal of Psychology, 21, 159-173. http://dx.doi.org/10.1111/j.1467-9450.1980.tb00356.x

Milner, A. D., \& Goodale, M. A. (1995). The visual brain in action. Oxford: Oxford University Press.

Nunes, T., Bryant, P., \& Bindman, M. (2006). The effects of learning to spell on children's awareness of morphology. Reading and writing, 19, 767-787. http://dx.doi.org/10.1007/s11145-006-9025-y

Ravid, D. (2001). Learning to spell in Hebrew: Phonological and morphological factors. Reading and Writing, 14, 459-485. http://dx.doi.org/10.1023/A:1011192806656

Rubin, H. (1991). Morphological knowledge and writing ability. In R. M. Joshi (Ed.), Written Language Disorders (pp. 43-69). Boston: Kluwer Academic.

Rudel, R. G., Denckla, M. B., \& Broman, M. (1978). Rapid silent response to repeated target symbols by dyslexic and nondyslexic children. Brain and Language, 6, 52-62. http://dx.doi.org/10.1016/0093-934X(78)90043-3

Saiegh-Haddad, E. (2003). Linguistic distance and initial reading acquisition: The case of Arabic diglossia. Applied Psycholinguistics, 24, 431-451. http://dx.doi.org/10.1017/S0142716403000225

Saiegh-Haddad, E. (2004). The impact of phonemic and lexical distance on the phonological analysis of word and pseudowords in a diglossic context. Applied Psycholinguistics, 25, 495-512. http://dx.doi.org/10.1017/S0142716404001249

Saiegh-Haddad, E., \& Geva, E. (2008). Morphological awareness, phonological awareness, and reading in English-Arabic bilingual children. Reading and Writing, 21, 481-504. http://dx.doi.org/10.1007/s11145-007-9074-x

Senechal, M. (2000). Morphological effects in children's spelling of French words. Canadian Journal of Experimental Psychology, 54, 7685. http://dx.doi.org/10.1037/h0087331

Share, D. L. (1995). Phonological recoding and self-teaching: Sine qua non of reading acquisition. Cognition, 55, 151-218. http://dx.doi.org/10.1016/0010-0277(94)00645-2

Snowling, M. (2001). From language to reading and dyslexia. Dyslexia, 7, 37-46. http://dx.doi.org/10.1002/dys. 185

Snowling, M. J., Goulandris, N., \& Defty, N. (1996). A longitudinal study of reading development in dyslexic children. Journal of Educational Psychology, 88, 653-669.

http://dx.doi.org/10.1037/0022-0663.88.4.653 
Stanovich, K. E. (1986). Matthew effects in reading: Some consequences of individual differences in the acquisition of literacy. Reading Research Quarterly, 21, 360-406.

http://www.jstor.org/stable/747612

Stanovich, K. E. (1988). Explaining the differences between the dyslexic and garden-variety poor reader: The phonological-core variabledifference model. Journal of Learning Disabilities, 21, 590-604. http://dx.doi.org/10.1177/002221948802101003

Taha, H. Y. (2013). Reading and spelling in Arabic: Linguistic and orthographic complexity. Theory and Practice in Language Studies, 3, 721-727. http://dx.doi.org/10.4304/tpls.3.5.721-727

Taha, H., Ibrahim, R., \& Khateb, A. (2013). How does Arabic orthographic connectivity modulate brain activity during visual word recognition: An ERP study. Brain Topography, 26, 292-302. http://dx.doi.org/10.1007/s10548-012-0241-2

Taha, H., \& Saiegh-Haddad, E. (Submitted). Morphology and spelling in Arabic: Development and interface.

Tong, X. L., Deacon, S. H., Kirby, J. R., Cain, K., \& Parrila, R. (2011). Morphological awareness: A key to understanding poor reading comprehension in English. Journal of Educational Psychology, 103, 523534. http://dx.doi.org/10.1037/a0023495

Treiman, R. (1993). Beginning to spell: A study of first-grade children. New York: Oxford University Press.

Treiman, R., \& Bourassa, D. C. (2000). The development of spelling skills. Topics in Language Disorders, 20, 1-18. http://dx.doi.org/10.1097/00011363-200020030-00004

Vidyasagar, T. R., \& Pammer, K. (1999). Impaired visual search in dyslexia relates to the role of the magnocellular pathway in attention. Neuroreport, 10, 1283-1287.

http://dx.doi.org/10.1097/00001756-199904260-00024

Wagner, R. K., \& Torgesen, J. K. (1987). The nature of phonological processing and its causal role in the acquisition of reading skills. Psychological Bulletin, 101, 192-212.

http://dx.doi.org/10.1037/0033-2909.101.2.192

Wolf, M., \& Bowers, P. G. (1999). The double-deficit hypothesis for the developmental dyslexias. Journal of Educational Psychology, 91, 415-438. http://dx.doi.org/10.1037/0022-0663.91.3.415

Wolf, M., Bowers, P. G. \& Biddle, K. (2000). Naming-speed processes, timing, and reading: A conceptual review. Journal of Learning Disabilities, 33, 387-407.

http://dx.doi.org/10.1177/002221940003300409

Ziegler, J. C., \& Goswami, U. (2005). Reading acquisition, developmental dyslexia, and skilled reading across languages: A psycholinguistic grain size theory. Psychological Bulletin, 131, 3-29. http://dx.doi.org/10.1037/0033-2909.131.1.3

Ziegler, J. C., Bertrand, D., Tóth, D., Csépe, V., Reis, A., Faísca, L., Saine, N., Lyytinen, H., Vaessen, A., \& Blomert, L. (2010). Orthographic depth and its impact on universal predictors of reading: A cross-language investigation. Psychological Science, 21, 551-559. http://dx.doi.org/10.1177/0956797610363406 